\title{
RANCANG BANGUN TRAINER ELEKTRONIKA DAYA: CONTROLLED AND UNCONTROLLED RECTIFIERS
}

\author{
Doni Tri Putra Yanto $^{1)}$, Rahmat Hidayat ${ }^{1)}$, Hamdani ${ }^{1)}$ \\ ${ }^{1)}$ Dosen Jurusan Teknik Elektro Universitas Negeri Padang, Padang
}

\begin{abstract}
This study discusses about the design process of Power Electronics Trainer as Learning Media or practicum equipment in the Power Electronics Practicum learning process, the unavailability of Practical Tool Practicum and Media that can help the implementation of the Power Electronics Learning Process into the background of this research. The research Stage of the Trainer Designation begins with the Design Stage, Product Production Stage, and Laboratory Feasibility Test Stage. This research produces a product in the form of a Power Electronic Trainer specifically for controlled and uncontrolled rectifiers that can be applied in the Power Electronics Practicum learning process. This trainer is made to be able to accommodate all learning materials about 1 phase and 3 phase rectifiers and the use of passive filters such as capacitors and inductors. The Power Electronics Trainer is expected to optimize the implementation of the Power Electronics Practicum Learning Process. Especially can help students in understanding theories about Power Electronics.
\end{abstract}

Keywords: Design Process, Power Electronic Trainer, Power Electronic Learning Process,

\section{PENDAHULUAN}

Pelaksanaan proses pembelajaran ilmu eksakta yang baik dan efektif membutuhkan sebuah peralatan atau media yang mampu mengkonkritkan materi yang secara garis besar bersifat abstrak, terutama dalam proses pembelajaran praktikum, pembelajaran praktikum merupakan proses pembelajaran yang berfungsi mengkongkritkan teori-teori yang bersifat abstrak. Oleh karena itu, maka ketersedian media pembelajaran praktikum yang baik dan memadai sangat mempengaruhi pelaksanaan proses pembelajaran tersebut, baik bagi mahasiswa maupun dosen yang ikut serta dan melaksanakan proses pembelejaran.[3][12][11].

Kehadiran media pembelajaran dalam proses pembelajaran praktikum sangat dibutuhkan karena media merupakan salah satu unsur vital yang dapat mempengruhi pelaksanaan proses pembelajaran praktikum, proses pembelajaran praktikum pada pelaksanaannya sering tidak optimal diakibatkan dari media pembelajaran yang tidak tersedia, tidak sesuai dengan materi pembelajaran, serta media pembelajaran yang tidak praktis dalam penggunaannya sehingga dapat meperbesar jumlah waktu yang dibutuhkan dalam pelaksanaan proses pembelajaran. [4][7]. Terutama untuk proses pembelajaran yang memiliki karakteristik materi yang bersifat abstrak yang membutuhkan alat bantu untuk mengkongkritkannya sehingga membuat mahasiswa mengerti dan mengalami proses pembelajaran dengan baik.

Praktikum Elektronika Daya merupakan salah satu proses pembelajaran yang harus diikuti oleh setiap mahasiswa Teknik Elektro Industri, Fakultas Teknik Universitas Negeri Padang. Proses pembelajaran ini merupakan proses pembelajaran lanjutan dari pembelajaran teori Elektronika Daya. Materi yang terkandung didalam proses pembelajaran ini banyak yang bersifat abstrak dan sulit dikongkrit jika hanya menggunakan media papan tulis atau presentasi lainya. Proses pembelajaran ini membutuhkan proses praktikum untuk pengujian dan pembuktian teori yang abstrak. Untuk mewujudkan proses pembelajaran yang baik pada praktikum ini maka dibutuhkan sebuah peralatan yang dapat dijadikan sebagai media praktikum mahasiswa yang praktis serta mampu mengakomodasi materi pembelajaran Elektronika Daya. [2][3] Selama ini, dalam pelaksanaannya media yang digunakan masih berupa papan rangkaian sederhana dengan alat ukur dan komponen yang terpisah. Sehingga membuat mahasiswa kesulitan dalam melaksanakan praktikum serta waktu yang digunakan pada proses pembelajaranpun menjadi relatif lebih lama. Akibatnya, pada akhir semester terdapat beberapa materi pembelajaran yang tidak tersampaikan atau dipraktekkan oleh mahasiswa karena keterbatasan waktu pelaksanaan pembelajaran setiap semesternya. Hal ini tentu sangat berpengaruh terhadap hasil belajar serta pencapaian dari tujuan pelaksanaan sebuah proses pembelajaran. ketidaktuntasan pelaksanaan proses pembelajaran mengakibatkan pemahaman mahasiswa terhadap materi pembelajaran menjadi berkurang dan tidak tuntas. Inilah yang nantinya akan berpengaruh terhadap proses pembelajaran berikutnya. Terutama untuk proses pembelajaran yang memiliki karakteristik materi pembelajaran yang relatif

\footnotetext{
${ }^{1}$ Korespondensi penulis: Doni Tri Putra Yanto, Telp 085355194538, donitriputra@ft.unp.ac.id
} 
sama atau lanjutan dari materi yang ada pada proses pembelajaran ini. Hal inilah yang menjadi latar belakang dilakukan penelitian tentang rancang bangun trainer elektronika daya pada proses pembelajaran elektronika daya. Dengan tujuan menghasilkan sebuah peralatan atau media pembelajaran praktikum untuk mengoptimalkan proses pembelajaran Praktikum Elektronika Daya.

\section{METODE PENELITIAN}

Penelitian ini dibagi menjadi tiga tahap utama yaitu tahap desain, tahap pembuatan, dan tahap ujicoba kelayakan dilaboratorium, ketiga tahap ini dilaksanakan secara berurutan dan runut agar dapat menghasilkan produk berupa trainer yang benar-benar cocok dan sesuai dengan yang dibutuhkan dalam proses pembelajaran praktikum. Serta mampu mencapai tujuan penelitian yang sudah direncanakan.

a. Desain

Desain ini mencakup semua kegiatan menyusun dan merencanakan desain awal dari trainer yang akan dibuat. proses pembuatan desain berdasarkan analisis kebutuhan yang dilakukan dengan menganalisis materi pembelajaran yang diajarkan dan analisis karakteristik mahasiswa pada saat mengikuti proses pembelajaran praktikum. Masukan-masukan mengenai kebutuhan ini didapatkan melalui hasil observasi lapangan yang dilakukan pada proses pembelajaran praktikum Elektronika Daya di Jurusan Teknik Elektro FT-UNP. Selain itu, informasi mengenai kebutuhan ini juga didapatkan dari masukan-masukan yang disampaiakn oleh dosen pengampu mata kuliah Praktikum Elektronika Daya tersebut. Desain akan selalu dikonsultasikan dengan dosen pengampu mata kuliah agar benar-benar sesuai dengan kebutuhan praktikum.[5][6]

b. Pembuatan Produk

Pembuatan produk mencakup semua kegiatan pembuatan produk berdasarkan desain akhir yang telah selesai dilaksanakan pada tahap sebelumnya. Dalam proses pembuatan ini dibagi menjadi pekerjaan mekanik dan pekerjaan elektrik. Pekerjaan mekanik berhubungan dengan semua kegiatan pengerjaan aspek mekanis produk seperti pembuatan kotak, pembuatan wadah isolator, pembuatan papan rangkaian dan lain sebagainya yang berhubungan dengan aspek mekanis. Sedangkan pekerjaan elektrik adalah pengerjaan yang berhubungan dengan pengerjaan kelistrikan seperti pemasangan komponen, pembentukan rangkaian, pemasangan komponen suplay kelistrikan dan lain sebagainya yang berhubungan dengan pengerjaan kelistrikan produk. [3][7]

c. Ujicoba Kelayakan

Ujicoba kelayakan ini mencakup semua kegiatan ujicoba laboratorium terhadap produk/alat yang telah dibuat pada proses sebelumnya. Sebelum diterapkan dalam kegiatan pembelajaran semua aspek penting dalam trainer yang dihasilkan harus melalui uji coba kelayakan. Tujuan dari ujicoba kelayakan ini adalah memastikan alat yang dibuat telah memenuhi unsur kelayakan, kebenaran, serta standar yang sudah ditetapkan. Sehingga benar-benar bisa diterapkan dalam kegiatan praktikum oleh mahasiswa dan memiliki tingkat keamanan yang tinggi pada saat digunakan. Baik keselamatan peralatan maupun kesalamatan manusia yang merupakan standar utama dalam penggunaan alat-alat kelistrikan.[9][10][12]

\section{HASIL DAN PEMBAHASAN}

Berdasarkan tujuan penelitian yang telah dirumuskan maka penelitian ini akan mengungkapkan hasil berupa rancang bangun sebuah peralatan praktikum yakni Trainer Elektronika Daya yang dapat digunakan dan diterapkan sebagai peralatan bantu mahsiswadalammelaksanakanproses pembelajaran praktikum. Sesuaidengan tahap-tahap penelitian yang telah dijelaskan sebelumnya maka dapat dikemukakan hasil dan pembahasan penelitian seperti berikut.

a. Desain

Trainer Elektronika Daya yang akan dibuat adalah sebuah alat bantu atau media dalam pelaksanaan proses pembelajaran praktikum, untuk itu dibutuhkan analisis karakteristik materi pembelajaran agar trainer yang dihasilkan benar-benar mampu mengakomodasi setiap materi dalam proses pembelajaran. Praktikum Elektronika Daya merupakan salah satu proses pembelajaran yang harus diikuti oleh setiap mahasiswa Teknik Elektro Industri, materi yang dibahas dalam proses pembelajaran ini yaitu, Penyearah Tak Terkendali yang melitputi, 1 fasa Setengah Gelombang, 1 Fasa Gelombang Penuh, 3 Fasa Setengah Gelombang, 3 Fasa Gelombang Penuh, Penggunaan Filter L, Penggunaan Filter L dan C. Kemudian untuk Penyearah Terkendali meliputi, Penyalaan SCR, Sudut Penyalaan SCR, 1 Fasa Setengah Gelombang, 1 Fasa Gelombang Penuh, 3 Fasa Setengah Gelombang, 3 Fasa Gelombang Penuh, Penggunaan Filter L dan 
C. [1][2][4] Maka dalam pembuatan desain harus mempertimbangkan kemampuan peralatan yang akan dibuat mampu mengakomodasi semua materi praktikum penyearah (rectifier) tersebut. Berdasarkan hasil observasi lapangan maka terlihat dibutuhkan media atau peralatan praktikum yang sudah tersedia menjadi satu kesatuan dan dikemas secara praktis, karena dengan penempatan dan alat yang terpisah-pisah seperti yang masih digunakan pada saat sekarang ini sering menghabiskan waktu sehingga penggunaan waktu pembelajaran tidak efektif.

Berdasarkan analisis tersebut maka dibuatlah desain trainer yang merupakan gabungan dari semua alat dan bahan yang dibutuhkan dalam pelaksanaan proses pembelajaran praktikum Elektronika Daya. Trainer dibuat dalam bentuk kotak atau box sehingga aman dan nyaman untuk dipindah-pindahkan. Suplay Listrik yang dibutuhkan untuk trainer adalah listrik 1 fasa dan 3 fasa sesuai dengan kebutuhan dari materi pembelajaran. desain trainer kemudian dibuat dengan menggunakan aplikasi Auto CAD dan Visio. Hasil akhir desain dari trainer Elektronika Daya ini disajikan pada gambar 1.

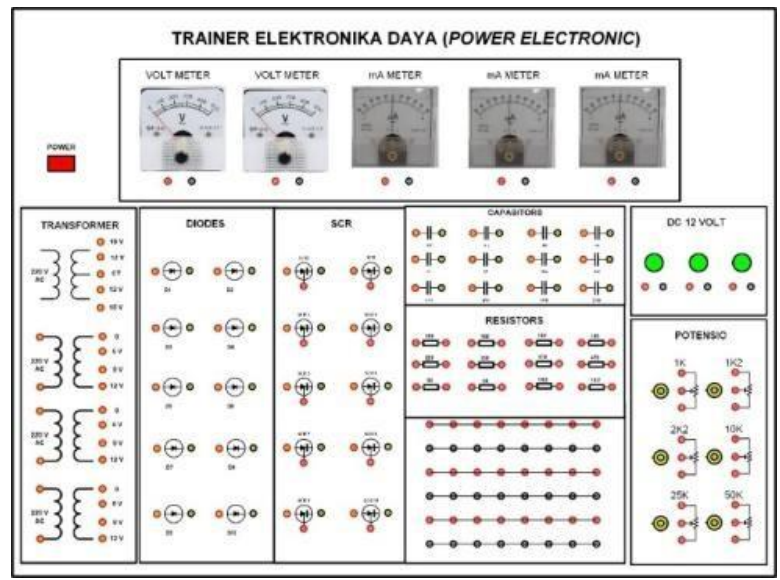

Gambar 1. Desain Trainer Elektronika Daya

\section{b. Pembuatan Produk}

Desain akhir yang telah direncanakan dan dibuat pada proses sebelumnya dijadikan pedoman dan acuan dalam melaksanakan kegiatan pembuatan produk. Pembuatan produk ini secara garis besar dibagi menjadi dua jenis pengerjaan yaitu pengerjaan mekanik dan pengerjaan elektrik. Kegiatan awal yang dilakukan adalah pengerjaan mekanik meliputi pembuatan BOX yang terbuat dari kayu dengan ukuran 640 X 480 X $170 \mathrm{~mm}$. Kemudian pembuatan papan rangkaian yang terbuat dari Acrilic dengan ukuran $640 \mathrm{X}$ $480 \times 5 \mathrm{~mm}$.

Pengerjaan kelistrikan adalah kegiatan pemasangan semua komponen-komponen yang dibutuhkan dalam trainer tersebut. Termasuk suplay arus listrik yang dibutuhkan baik yang 3 fasa maupun 1 fasa. Komponen-komponen yang dibutuhkan disesuaikan dengan kebutuhan komponen pada saat praktikum. Komponen-komponen yang dibutuhkan tersebut antara lain Dioda, SCR, Trafo CT 5 Ampere, Trapo 5 Ampere, Alat ukur Arus, Alat ukur Tegangan. Resisitor, Kapasitor, Potensio, Lampu DC 12 Volt 32 Watt dan lain sebagainya sesuai dengan kebutuhan untuk praktikum berdasarkan materi yang akan dipelajari pada proses pembelajaran tersebut. Selain itu, Trainer tersebut didalamnya juga disediakan papan rangkaian yang fungsinya adalah untuk komponen eksternal jika seandainya ada komponen tambahan diluar komponen utama yang tersedia pada trainer tersebut. Trainer ini diberi nama Trainer Elektronika Daya HDZ-PE001, hasil akhir pembuatan trainer HDZ-PE001 ini disajikan pada gambar 2. 


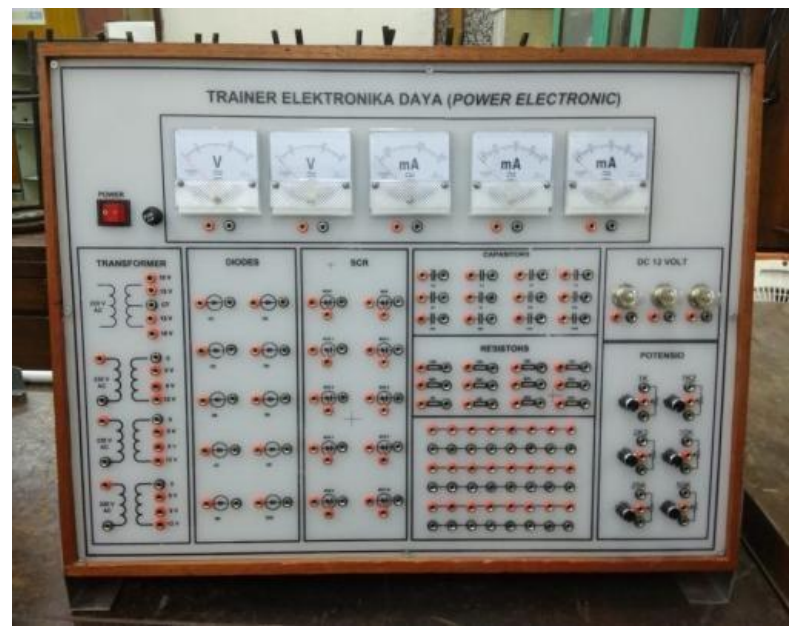

Gambar 2. Hasil Akhir Pembuatan Trainer Elektronika Daya HDZ-PE001

\section{c. Uji Coba Kelayakan}

Ujicoba kelayakan ini mencakup semua kegiatan ujicoba produk terutama pengujian kelistrikan yang dilakukan di labor konversi energi Jurusan Teknik Elektro Fakultas Teknik Universitas Negeri Padang. Uji coba kelayakan ini dilaksanakan dengan mengukur parameter suplay kelistrikan baik untuk tiga fasa maupun tiga fasa selain itu juga dilakukan pengukuran arus beban maksimum dan arus beban minimum, pengukuran ini dilakukan untuk memastikan bahwa parameter-parameter kelistrikan yang ada pada trainer berda pada taraf yang baik dan sesuai dengan standar yang telah ditetapkan terutama untuk dapat digunakan dalam proses pembelajaran Praktikum Elektronika Daya. Hasil pengukuran parameter- parameter kelistrikan tersebut disajikan pada tabel berikut.

Tabel 1. Hasil Pengukuran Prameter Kelistrikan Trainer

\begin{tabular}{|c|c|c|c|c|c|}
\hline \multirow[t]{2}{*}{ No } & \multirow[t]{2}{*}{ Urutan Fasa } & \multicolumn{2}{|c|}{ Tegangan } & \multirow{2}{*}{$\begin{array}{c}\text { Arus } \\
\text { Maksimum } \\
\text { (Ampere) }\end{array}$} & \multirow[t]{2}{*}{ Keterangan } \\
\hline & & $\begin{array}{c}\text { Standar } \\
\text { (Volt) }\end{array}$ & $\begin{array}{c}\text { Pengukuran } \\
\text { (Volt) }\end{array}$ & & \\
\hline 1 & Fasa R-N & 220 & 221 & 3 & Normal \\
\hline 2 & Fasa S-N & 220 & 219 & 3 & Normal \\
\hline 3 & Fasa T-N & 220 & 221 & 3 & Normal \\
\hline 4 & Fasa R-S & 380 & 382 & 3 & Normal \\
\hline 5 & Fasa S-T & 380 & 382 & 3 & Normal \\
\hline 6 & Fasa T-S & 380 & 380 & 3 & Normal \\
\hline
\end{tabular}

Berdasarkan data yang disajikan pada tabel 1 diatas dapat diketahui bahwa untuk tegangan dan arus suplay berada pada taraf normal walaupn terdapat sedikit perbedaan antara pengukuran dan standar yang ditetapkan namun perbedaan tersebut masih berada pada taraf toleransi sebesar 5\%. Hasil pengujian ini membuktikan secara kelistrikan sumber listrik yang digunakan dan yang masuk kedalam trainer praktikum telah sesuai dengan standar kelistrik yang telah ditetapkan untuk penggunaan di Indonesia (PUIL 2011).

Setelah pengujian parameter tersebut dilakukan pula pengujian komponen-komponen ketika terhubung menjadi satu kesatuan rangkaian. Pengujian dilakukan dengan mempraktikan salah satu materi yakni penyearah 1 fasa gelombang penuh. Pengujian ini dilakukan untuk mengetahui tingkat kebenaran dari alat yang telah dibuat terutama kaitannya dengan fungsinya sebagai peralatan atau media pembelajaran praktikum pada proses pembelajaran Praktikum Elektronika Daya. Gambar rangkaian pengujian disajikan pada gambar 3 berikut. 

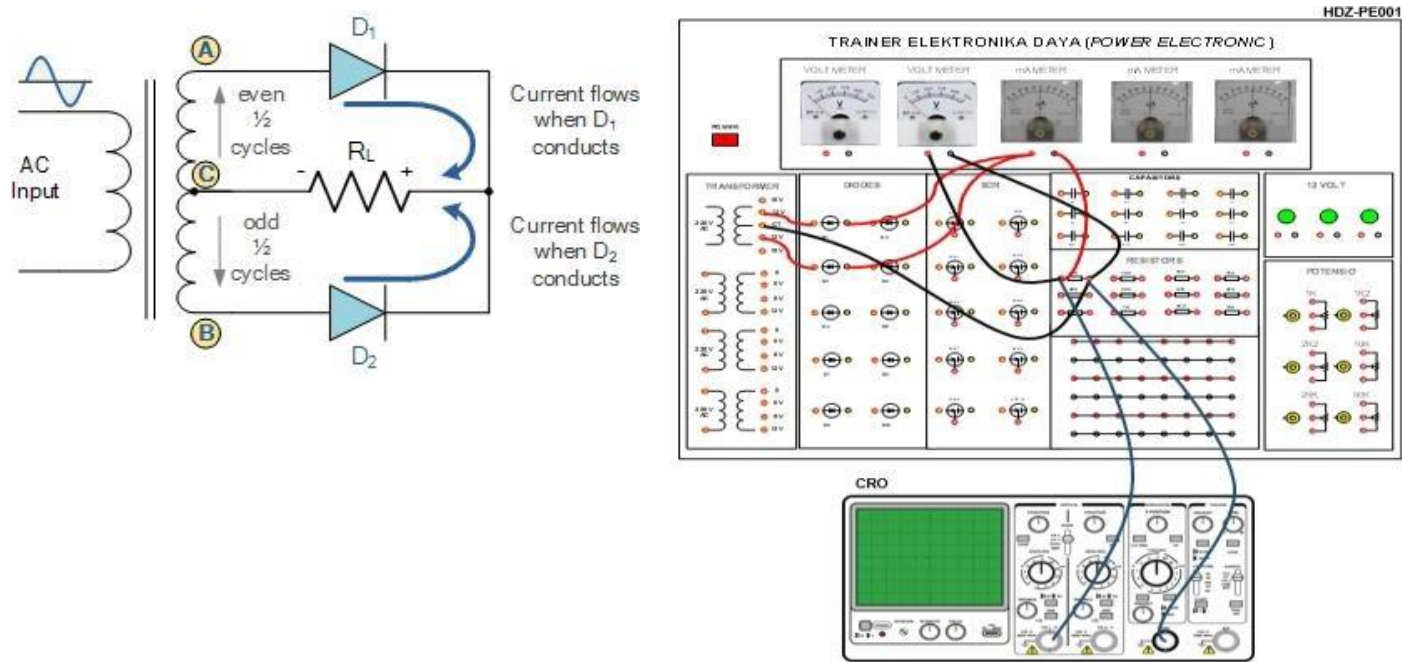

Gambar 3. Rangkaian Pengujian Komponen Trainer

Rangkaian yang dibuat pada trainer tersebut dipsuplay dengan tegangan 12 Volt AC yang didapatkan melalui keluaran trafo,kemudian dilakukan pengukuran, hasil pengukuran kemudian diabandingkan dengan hasil perhitungan berdsarkan rumus yang telah ditentukan. Pada pengujian kali ini berlaku rumus perhitungan sebagai berikut.

$$
\begin{aligned}
& V_{\text {dg }}=0.63666 V_{m} \\
& I_{d c}=\frac{0.6366 V_{m}}{R} \\
& V_{r m s}=0.707 V_{m} \\
& I_{r m s}=\frac{0.707 V_{m}}{R}
\end{aligned}
$$

\begin{tabular}{|c|c|c|c|c|c|c|}
\hline \multirow{3}{*}{$\begin{array}{c}\text { Beban } R \\
(\Omega)\end{array}$} & \multicolumn{2}{|c|}{ Input } & \multirow{2}{*}{\multicolumn{2}{|c|}{ Idc (mA) }} & \multirow{2}{*}{\multicolumn{2}{|c|}{ Vdc (Volt) }} \\
\hline & \multirow{2}{*}{$\begin{array}{c}\mathrm{Vm} \\
(\mathrm{Cm})\end{array}$} & \multirow{2}{*}{$\begin{array}{l}\text { Vrms } \\
\text { (Volt) }\end{array}$} & & & & \\
\hline & & & Hitung & Ukur & Hitung & Ukur \\
\hline 100 & 10 & 7,07 & 63,66 & 62,90 & 6,366 & 6 \\
\hline 150 & 10 & 7,07 & 42,44 & 43,00 & 6,366 & 6,1 \\
\hline 200 & 10 & 7,07 & 31,83 & 32 & 6,366 & 6,1 \\
\hline 220 & 10 & 7,07 & 28,93 & 29 & 6,366 & 6 \\
\hline 300 & 10 & 7,07 & 21,22 & 22,01 & 6,366 & 6 \\
\hline 400 & 10 & 7,07 & 15,91 & 16,02 & 6,366 & 6,1 \\
\hline 440 & 10,05 & 7,12 & 14,53 & 15 & 6,397 & 6,2 \\
\hline 470 & 10 & 7,07 & 13,54 & 14,003 & 6,366 & 6,3 \\
\hline $1 \mathrm{k}$ & 10 & 7,07 & 6,37 & 7,302 & 6,366 & 6,3 \\
\hline
\end{tabular}

Hasil dari pengujian komponen trainer Elektronika Daya pada uji Laboratorium kali ini disajikan pada Tabel 2 berikut.

Tabel 2. Hasil Pengujian Rangkaian Trainer

Berdasarkan tabel diatas maka dapat diketahui bahwa terdapat perbedaan antara hasil pengukuran dengan hasil perhitungan pada beberapa hasil pengukuran, namun jika diperhitungkan maka selisih dari hasil perhitungan dan pengukuran berada pada taraf toleransi 5\% dengan demikian maka dapat dinyatakan bahwa trainer Elektronika Daya HDZ-PE001 telah memenuhi standar laboratorium terutama untuk pelaksanaan 
pembelajaran Praktikum Elektronika Daya pada Labor Konversi Energi Jurusan Teknik Elektro FT-UNP. Terutama jika ditinjau dari ketepatan dalam melakukan pengukuran dan pengujian rangkaian percobaan.

\section{KESIMPULAN}

Dari pelaksanaan penelitian ini maka dapat disimpulkan bahwa dalam pelaksanaan pembelajaran praktikum dibutuhkan sebuah peralatan praktikum yang mampu membantu mengoptimalkan hasil dan proses pembelajaran praktikum dilaboratorium, selain itu alat atau media yang akan digunakan harus praktis dan efektif dalam penggunaan waktu proses pembelajaran. Trainer Elektronika Daya HDZ-PE001 merupakan salah asatu alternatif pilihan peralatan praktikum yang telah dibuat dan dikembangkan sesuai dengan kebutuhan dari prose pembelajaran praktikum Elektronika Daya, selain itu berdasarkan beberapa pengujian kelayakan di laboratorium menunjukkkan bahwa traien yang dibuat telah memnuhi standar kelayakan dan keamanan untuk dapat diterapkan dalam proses pembelajaran Praktikum Elektronika Daya. Trainer ini akan selalu mengalami perbaikan dan perkembangan seiring dengan perkembangan kebutuhan dari materi pembelajaran yang akan diakomodasi oleh trainer ini.

\section{DAFTAR PUSTAKA}

Ansyar, Rayandra, 2012,Kreatif Mengembangkan Media Pembelajaran, Jakarta: Gaung Persada.

Arief, Sardiman dkk., 2005,Media Pembelajaran (Pengertian Pengembangan Pemanfaatan), Jakarta : Raja Wali Press.

Azhar, Arsyad, 2010,Media Pembelajaran, Jakarta: Raja Wali Press.

Batarseh, Issa, 2004,Power Electronic Circuits, New York: John Willey

Blaabjerg, Frede, 2017, Control of Power Electronic Converters and System, Cambridge : Mara Corner

Erickson, Robert, 2009,The Fundamentals of Power Electronic, Newcastle : Chapman \& Hall

Grahn, Holger, 2014,Introduction to Semiconductor Physics, New Jersey: World Scientific.

Hamidi, Farideh, 2010, "Comparison of the Training Effects of Trainer Media and Non-Trainer Media on Increasing Learning Outcomes, in Physics Science Course". ScienceDirect. Department of EducationShahid Rajaee Teacher Training University, Iran.

Heinich, dkk., 2005,Instructional Technology and Media for Learning. New Jersey, Columbus, Ohio: Pearson Merrill Prentice Hall, Upper Saddle River

Jungel, Ansgar, 2012,Transpor Equations for Semiconductor, Austria : Springer

Pollefliet, Jean. 2016,Power Electronic : Switches and Converter, New Jersey : Kattie Hammon

Reddy, Rama, 2000,Fundamentals of Power Electronics. New Delhi : Narosa Publishing House

Suharsimi, Arikunto. 2007. Dasar-dasar Evaluasi Pendidikan. Jakarta : Bumi Aksara

Sukardi, S., Puyada, D., Wulansari, R. E., \& Yanto, D. T. P. (2017). The validity of interactive instructional media on electrical circuits at vocational high school and technology. The 2nd INCOTEPD, 2017, 21-22.

Trianto, 2009,Mendesain Model Pembelajaran Inovatif Progresif. Jakarta : Kencana.

Yanto, D. T. P., Sukardi, S., \& Puyada, D. (2017). EFFECTIVENESS OF INTERACTIVE INSTRUCTIONAL MEDIA ON ELECTRICAL CIRCUITS COURSE: THE EFFECTS ON STUDENTS COGNITIVE ABILITIES. Proceedings of 4rd International Conference On Technical And Vocational Education And Training, 2017, 75-80. 


\section{UCAPAN TERIMA KASIH}

Ucapan terima kasih penulis haturkan kepada Rektor Universitas Negeri Padang dan ketua Lembaga Penelitian dan Pengabdian Masyarakat (LP2M) Universitas Negeri Padang yang telah memberi kesempatan dan pendanaan agar penelitian ini dapat dilaksanakan, kemudian ucapan terima kasih juga dihaturkan kepada rekanrekan dosen jurusan Teknik Elektro Fakultas Teknik Universitas Negeri Padang, Teknisi Laboratorium, Mahasiswa, dan semua pihak yang telah banyak membantu dan berkontribusi demi terlaksananya penelitian ini dengan baik dan sesuai dengan yang direncanakan. 